\title{
REVISTAMARACANAN
}

\section{História das Religiões: da construção de uma disciplina aos seus desafios atuais}

\author{
History of Religions: from building a discipline to its current challenges
}

\author{
Bruna Soalheiro* \\ Universidade do Estado do Rio de Janeiro \\ Fernando Torres Londoño** \\ Pontifícia Universidade Católica de São Paulo
}

Na segunda metade do século XVIII, mais especificamente em 1757, o filósofo iluminista escocês David Hume publicou uma obra chamada The Natural History of Religion, considerada uma espécie de percursora dos estudos contemporâneos do campo da História das Religiões. Desde então, a construção do "religioso" como objeto de investigação é um tema que interessa à História e as demais Ciências Humanas de forma incessante, especialmente após a consolidação destes saberes e discursos enquanto disciplinas autônomas e de reconhecida cientificidade. Filosofia, Antropologia, Sociologia, Psicologia, Psicanálise e História, cada uma à sua forma, interrogaram-se sobre a religião, as religiões e o fato religioso enquanto uma expressão da realidade social. Mais do que isso, a própria "história das religiões" (Religionswissenschaft) configurou-se, com Max Müller a partir da segunda metade do século XIX, como uma disciplina nova, cujos parâmetros e premissas estão lançados desde

\footnotetext{
${ }^{*}$ Bolsista de Pós-Doutorado (CAPES/PNPD) no Programa de Pós-graduação em História da Universidade do Estado do Rio de Janeiro. Doutora em História Social pela Universidade de São Paulo (USP) e em Histoire et civilisations pela École des Hautes Études en Sciences Sociales; Mestre em História Social pela USP; e, Graduada em História pela Universidade Federal Fluminense. (brunasoalheiro@usp.br)

CV Lattes: http://lattes.cnpq.br/0348245873351423.

** Professor Titular do Departamento de História e do Programa de Pós-graduação em Ciências da Religião da Pontifícia Universidade Católica de São Paulo. Doutor em História Social pela Universidade de São Paulo. (fertorresbracol@gmail.com)

CV Lattes: http://lattes.cnpq.br/0707506010946254.
} 
pelos menos os anos 1900, e incessantemente renovados pelas escolas francesas, italianas e demais iniciativas sistemáticas de investigação.

Se em sua origem a matriz judaico-cristã determinou, em certa medida, o enquadramento e as analogias possíveis, a partir das abordagens comparativas, a pluralidade das pesquisas desenvolvidas sustenta a diversidade temática e metodológica, além da riqueza analítica sobre as quais a História das Religiões se funda, se dissemina e se sustenta. Este dossiê foi pensado justamente para reunir pesquisas atualmente em desenvolvimento que se dedicam a esta temática, em especial em sua articulação com outros campos, como o da cultura, o da política e o das relações sociais.

Assim, observamos que temas como missões religiosas, culto, liturgia, teologia, e moral, além de seu aspecto de mediação do sagrado, também são analisados em função de sua importância no âmbito das disputas entre alteridades e construções de identidade; das tensões entre as diversas formas de entender e representar o religioso; das relações de gênero; de suas implicações com projetos econômicos e seus efeitos na vida material; e de sua instrumentalização para o estabelecimento de lugares e hierarquias sociais. Outro aspecto interessante observado nos estudos aqui publicados diz respeito à relação entre a disseminação de uma determinada religião e a (re)estruturação do espaço, seja em áreas rurais ou de fronteira, seja em áreas de crescente e acentuada urbanização, seja em contextos coloniais ou na contemporaneidade. Isso diz da potencialidade da História das Religiões enquanto um espaço discursivo e historiográfico que propicia o diálogo entre diferentes campos do saber, na medida em que viabiliza e materializa estudos que dialogam com a teologia, a geografia, a antropologia, a sociologia, a arquitetura e, evidentemente, a história.

A disseminação do cristianismo e da vida cristã no período moderno, por exemplo, é abordada no artigo Um santo brâmane: a vida e santidade do oratoriano José Vaz na obra de Sebastião do Rego. A partir da análise de uma fonte documental do século XVIII, Ana Paula Sena Gomide aborda as questões acerca da formação de um clero nativo em um espaço oriental não colonial. Em um contexto de franca disputa entre portugueses e holandeses - isto é, entre católicos e protestantes - a autora acompanha a trajetória de um cristão de origem brâmane que de Goa parte para o Ceilão. Ressaltando a importância da Congregação do Oratório de Goa na disseminação do cristianismo na região, a leitura nos permite perceber as complexidades da extrapolação da presença cristã para além os limites do Estado da Índia.

Ainda no contexto da Época Moderna, a conduta exemplar de uma vida religiosa, abordada a partir da leitura de uma fonte do século XVIII, é o tema do artigo "E se o frade quiser ser perfeitinho": instruções para uma conduta exemplar do clero regular português no século XVIII. Esta contribuição traz para o debate os aspectos morais que muitas vezes estão associados ao tema da religião e seus respectivos desdobramentos na vida social daquele tempo, lançando luz ao contexto da Reforma católica, isto é, abordando o tema da conduta moral adequada como indício de uma reestruturação da Igreja Católica e sua 
acentuada preocupação com a regulação das práticas religiosas. Tece-se aqui, então, um diálogo entre a moralidade e o contexto reformado, debatendo ortodoxia e normatização de condutas e práticas sociais.

Em O romance missionário-protestante Candida: autoria feminina e relações de gênero na obra de Mary Hoge Wardlaw (séc. XIX-XX), as relações de gênero, ação missionária e atividade escrita são temas articulados. As imbricações entre gênero e religião são analisadas de forma complexa, a partir de um pertinente aporte teórico que respalda uma atenciosa análise textual. A religião, neste contexto, aparece como um meio que viabiliza a expressão das concepções de mundo de uma mulher protestante no final do século XIX, informando-nos das tensões entre os gêneros e as diminutas possibilidades de protagonismo feminino. As análises conduzidas por Sergio Willian de Castro Oliveira Filho neste artigo reiteram ainda um ponto central de dossiê aqui proposto: as possibilidades infinitas de problematizações e articulações que a história das religiões propicia, em especial tendo em conta a noção do religioso como aquilo que diz dos modos de vida e das visões de mundo de sujeitos singulares e de comunidades políticas.

A relação entre "civilizar", "colonizar" e "catequisar" é objeto do artigo Civilizar para colonizar en Urabá (Antioquia, Colombia), 1918-1940. A questão central - a produção de uma fronteira - é analisada levando em conta a atuação decisiva de uma ordem religiosa: os Carmelitas. Num contexto contemporâneo (início do século XX), observa-se como a atividade missionária assessorou iniciativas estatais de desenvolvimento econômico e material. A posição geográfica estratégica de Urabá, os projetos de extração mineral e florestal, abertura de ferrovias comunicando o interior da Colômbia com o Atlântico, a presença de uma comunidade indígena "não reduzida", a iniciativa evangelizadora: estes são os elementos apontados por Carolina María Horta Gaviria e analisados em conjunto sob o aporte teórico das noções de territorialidade e colonialidade do poder. Segundo o binômio progresso moral e progresso material, a questão religiosa - representada pela missão carmelita - é aqui analisada em seu papel "civilizatório", isto é, enquanto manifestação de uma violência simbólica que subsidiava um determinado agir político voltado para a desconstrução de um suposto "espaço selvagem".

Avançando mais um pouco na contemporaneidade, Marcello Felipe Duarte compõs, em A teologia da prosperidade na Igreja Universal do Reino de Deus e a demonização das religiões afro-brasileiras uma análise complexa e perspicaz dos aspectos sociais da disseminação das religiões neopentecostais e de sua teologia da prosperidade, especialmente no Brasil das últimas décadas. O foco na Igreja Universal do Reino de Deus, ao contrário de isolar o debate investigativo, é eficaz em demonstrar a construção de uma identidade social do fiel da IURD na mesma medida em que estabelece relações entre a formação deste ethos e as demais religiosidades do Brasil contemporâneo. Mais do que isso, o autor expõe de maneira muito pertinente a ambivalência do processo de demonização e assimilação de certas práticas rituais, as quais são ora relegadas ao campo do outro, ora apropriadas e legitimadas enquanto 
meios para se acessar o sagrado. Além das implicações destas lógicas de pertença na vida social, os aspectos da vida material também são destacados, a partir de uma noção de mercado de bens religiosos e da consolidação da teologia da prosperidade, cujos efeitos se fazem sentir na reiteração do poder de determinadas lideranças e no apelo que exercem nos fiéis.

Neste sentido, é muito rica a contribuição do artigo de Rodrigo Pereira \& André Leonardo Chevitarese Por uma Arqueologia dos Candomblés: contribuições da ciência do passado aos estudos dos fenômenos religiosos não só por trazer à análise o Candomblé enquanto uma forma de religiosidade afro-brasileira, mas também por incorporar metodologias interdisciplinares, fazendo permear em sua investigação Arqueologia, Antropologia e História.

O presente dossiê traz ainda duas notas de pesquisa, que têm como objetivo apresentar o estado presente de algumas investigações em andamento. A primeira delas, A atividade litúrgico-musical da ermida de Nossa Senhora dos Remédios: Expressão de uma identidade nobiliárquica da cidade de Angra nos séculos XVI e XVII, traz tema do religioso a partir de suas manifestações culturais e de suas implicações sociais no arquipélago dos Açores. A atividade musical, a liturgia e o estabelecimento e afirmação de uma nobreza local são temas que se articulam no artigo de Luís Henriques. A paisagem sonora, a estruturação do culto e os aspectos sócio hierárquicos são descritos de maneira a compor uma análise historiográfica rica e original, enfatizando a importância do patrocínio religioso e a projeção de influência e poder das famílias nobres locais.

A segunda nota 0 cristianismo na terra dos lamas: mais uma forma de sagrado chega ao Tibete (sec. XVII e XVIII), tem como objetivo debater o próprio conceito de religião e seus problemáticos usos, em especial em se tratando de investigações cujos recortes não se limitam ao chamado "Ocidente", isto é, quando se trata de analisar sistemas de crenças e práticas religiosas que não se filiam à tradição judaico-cristã ocidental. Pensando as complexidades dos diálogos inter-religiosos, está colocada em questão a pertinência da noção de religião, bem como de outros conceitos agregadores que nos informam mais de um dizer sobre o outro do que do outro ele mesmo. Procura-se debater em que medida categorias como "Budista" e "Hinduísta" são pertinentes e eficazes no discurso historiográfico, bem como refletir se, neste contexto, o cristianismo não seria apenas mais uma forma do sagrado, cuja a especificidade doutrinária e seus efeitos sócio-políticos são evidentes apenas da parte de um dos interlocutores que participam do diálogo.

Encerramos este dossiê com a entrevista realizada com o professor Adone Agnolin, na qual o professor e pesquisador da Universidade de São Paulo contextualiza o processo de surgimento e consolidação do religioso enquanto objeto/problema das ciências humanas, em especial da História. Com enfoque na Escola Italiana, Agnolin demonstra o desenvolvimento deste saber e deste discurso, problematizando seus limites e indicando caminhos possíveis 
para os desdobramentos de investigações neste campo. É, de fato, uma contribuição primorosa para este volume.

Esta edição da Revista Maracanan conta, ainda, com sete contribuições de temática livre. Na Nota de Pesquisa Fragmentos de (auto)imagem: notas sobre o Fundo Yvonne Jean no Arquivo Público no Distrito Federal (1911-1981), Rafael Pereira da Silva transita entre os arquivos pessoais, a memória e a escrita da história, para traçar uma trajetória intelectual da personagem título. Carolina Barcellos Ferreira, por sua vez, traz ao público uma Entrevista com Mariza Soares, tratando sobre a coleção de objetos africanos do Museu Nacional, e mais especificamente sobre a exposição "Kumbukumbu". Por fim, a seção "Artigos" encerra este número, com uma coletânea de textos de extrema qualidade: André Rocha Carneiro e Lúcia Maria de Assis, A organização dos comunistas na região Sul Fluminense no período pré-golpe civill-militar (Barra Mansa, Volta Redonda, Barra do Piraí e Piraí); André Luiz de Souza Oliveira Oliveira \& Thaddeus Gregory Blanchette, Lepra e Exílio: a biopolítica da monarquia havaiana no século XIX; Maria Aparecida de Menezes Borrego \& Jean Gomes de Souza, Os percursos das Notícias Práticas das Minas de Cuiabá e Goiás na capitania de São Paulo (séculos XVIII-XX); Cláudia Maria de Silva de Oliveira, Rendas e Gravatas: moda, identidade e gênero na Imprensa Ilustrada carioca, 19001914; Júlia Freire Perini \& Marcelo Durão Rodrigues da Cunha, Entre a repressão policial e o saber médico: o controle social da loucura no Espírito Santo entre o fim do século XIX e os anos 1950. 